\title{
The Influence of the Circulation Industry's Development in China-Based on the Scale of Circulation Industry and the Difference of Urban and Rural Structure
}

\author{
Zhang Yi-han \\ School of Economy, Shanghai University, Shanghai, China
}

Email address:

Phylliszyh@126.com

To cite this article:

Zhang Yi-han. The Influence of the Circulation Industry's Development in China_-Based on the Scale of Circulation Industry and the Difference of Urban and Rural Structure. Science Innovation. Vol. 5, No. 6, 2017, pp. 344-348. doi: 10.11648/j.si.20170506.12

Received: August 15, 2017; Accepted: August 22, 2017; Published: October 27, 2017

\begin{abstract}
The impact of the circulation industry on the upgrading of industrial structure can be considered from many levels. In this paper, we try to confirm the impact of circulation industry in China's three major areas to the industrial upgrading from three dimensions: the scale of the production-type circulation industry, the scale of the consumption-type circulation industry and the development of the gap between the urban and rural areas. In order to research the relationship, two groups of panal data which range in 1995-2008 and 2004-2015 time zones in 31 provinces and cities in China are selected, and the fixed effect model is used by STATA 12.0 software. Combined with the conclusions and regional economic characteristics, different policy recommendations are provided in the end.
\end{abstract}

Keywords: The Upgrading of Industrial Structure, The Scale of Circulation Industry,

Gap Between the Urban and Rural Areas, Three Major Areas in China

\section{流通业发展对我国三大区域产业结构升级的影响一一基于流通业 规模和城乡结构差异两个视角}

张艺馚

经济学院, 上海大学, 上海, 中国

邮箱

Phylliszyh@126.com

摘要：流通业对产业结构升级的影响可以从很多个层面进行考虑，本文选取中国31个省市区1995-2008及2004-2015两 个时间段的数据，运用STATA12.0软件使用固定效应模型，从生产型商贸流通业规模、消费型商贸流通业规模和流通 业发展城乡差距三个维度论证流通业发展状况对中国东中西三大地区产业升级的影响, 结合各地区的经济特征, 提出 相应的政策建议。

关键词: 产业结构升级, 商贸流通业, 流通业规模, 城乡差距 


\section{1. 引言与研究综述}

流通业是第三产业的重要组成部分，作为连接生产 与消费的重要纽带, 其在国民经济中的地位是不言而喻 的。流通业的发展能够实现信息在产业链各环节之间的 传递, 动态调整市场供求结构, 进而引导着各大产业及 其部门结构的调整、优化、升级, 最终推动地区产业结 构逐步趋于合理化，高度化。基于商贸流通业在产业结 构升级中的重要作用, 众多学者对于两者之间的关系从 多角度进行研究。

国内学者赵公民[1]、王晓东[2]、柇纲[3]就商贸流通业 发展与就业、城市化以及经济增长之间的关系进行了理论 与实证研究, 而商贸流通业发展对产业结构影响的研究相 对较少, 较早研究从2000年开始出现。吴沉、王传维[4]从 流通业对劳动力的转移和吸附角度探究流通业发展对产业 结构调整的作用; 宋则和赵凯[5]运用商贸流通业关联系数、 脉冲响应函数、方差分解模型探究商贸流通业的对中国产 业结构升级的影响。杨以文[6]实证分析了商贸流通业对江 苏经济、城市化进程和产业结构的影响, 发现江苏商贸流 通业与 GDP增长成正比, 对城市化的发展及产业结构的优 化升级具有显著的正向推动作用。朱黎明[7]年通过将商贸 流通业分为生产型和服务型两类, 分别研究对中国产业结 构的不同作用, 提出相应政策建议。宋艳萍 [8]运用灰色关 联方法, 研究发现商贸流通业在产业体系中的动态角色演 进可以分为二产推动流通业发展、三产拉动流通业发展和 商贸流通业独立发展三个阶段。张得银[9]将流通业发展定 义为流通产业规模、流通城乡结构、流通固定资产投资和 流通劳动投入水平, 从微观角度分析对不同区域产业结构 升级的影响。李罗 [10]从支持效应、集聚效应、带动效应和 蝴蝶效应四个方面阐述商贸流通业发展与产业结构升级的 耦合效应, 并提出相应政策建议。车久菊（2016）[11]以长 三角经济圈为例, 实证研究流通业发展规模、要素投入对 产业结构调整的作用机理, 发现城乡二元结构及资本有效 投入不足阻碍产业结构调节优化。王志楠（2017）[12]通过 研究表明流通业对中国三次产业发展均有正向促进作用, 但生产型流通业作用大于消费型流通业。

以上研究虽然确立了流通业对产业升级影响的理论 基础, 但实证分析不多, 且分析角度较为单一, 未结合中 国地区发展特性进行考察。本文结合中国三大区域目前经 济发展参差不齐的现状, 试图从生产型商贸流通业、消费 型商贸流通业发展规模以及商贸流通业发展城乡结构差 异三个角度来探究其对中国产业结构升级的影响, 一方面 有利于各地区从不同角度认识到流通业的发展对本地区 产业升级的影响方向, 另一方面有利于各地区结合自身经 济特征调节流通产业的发展侧重点。

\section{2. 流通产业对产业升级的作用机理}

\section{1. 流通业规模与产业结构升级}

\subsection{1. 协作效应}

商贸流通业具有连接供给端和需求端的能力, 其在连 接各地区经济发展、促进要素转移中具有较强的协作效应。
首先, 商贸流通业为第一产业的发展提供支持, 为农产业 外销提供途径, 加快其运转速度。其次, 商贸流通业降低 了第二产业的生产成本, 流通业形成的产业网络使得工业 企业以较低成本完成生产所需原材料、产成品的运送。最 后, 商贸流通业提升了第三产业的发展。它在发展过程中 形成区位选择优势, 产生集聚效应进而吸引更多同类企业 聚集, 增大了产业的竞争程度, 提高了地区第三产业的效 率。

\subsection{2. 制约效应}

商贸流通业的发展对其他产业在人力资源、社会资本 和土地资源等方面存在一定的侵占, 因此与其他产业发展 存在一定的资源争夺冲突。对于不同发展程度的地区, 流 通业发展水平不同对地区产业的集聚效应也存在差异, 发 展较好的地区流通业相对完善, 进一步吸收落后地区的资 源, 加剧了两地之间的发展差距, 马太效应由此产生。

\section{2. 流通业城乡结构与产业结构升级}

不同地区城乡之间流通业发展状况差异明显。一方面, 发展落后的乡镇流通设施不完善阻碍了当地优质农产品 进入城区, 也增加了城市商品进入乡村的成本, 导致整个 地区的产业升级进程受阻; 另一方面, 城乡之间流通水平 的差异引起的流通不畅, 增加了商品交易的周期, 降低了 社会再生产效率，这对于第二、第三产业的产出效益都无 利。

\section{3. 实证检验}

\section{1. 数据来源和变量选取}

本文实证中所有数据均来源于 《中国统计年鉴》和 wind数据库。因变量为产业结构升级指标, 自变量依据研 究对象不同分为生产型商贸流通业发展规模、消费型商贸 流通业发展规模和商贸流通业发展城乡差距。为了更加准 确地反映模型的计量效果, 我们将影响产业结构升级的几 个因素予以考虑, 添加技术进步指标、市场化进程指标、 外商直接投资指标作为控制变量。

1. 依据配地-克拉克关于第一、第二、第三产业低位 逐级递增的演化规律, 构建式（1）产业结构升级指数来 衡量产业升级:

$$
I U=1 * S_{1}+2 * S_{2}+3 * S_{3}
$$

$I U$ 表示产业结构升级指数, $S_{1} 、 S_{2} 、 S_{3}$ 分别表示 第一、第二、第三产业产值占GDP的比重。 $I U$ 越接近 1 表示产业结构的层级越低, $I U$ 接近 3 表示产业结构层级越 高。

2. 商贸流通业发展规模用流通业产值来表示, 即以交 通运输、仓储及邮电通信业产值 $C_{1}$ 表示生产型流通业规 模 $P R O \_v a l$, 以批发零售和住宿餐饮两类流通业产值之 和 $C_{2}$ 表示消费型流通业发展规模 $C O N_{-}$val 。由于数值较 大, 本文对流通业发展规模数据进行对数化处理。 


$$
\begin{gathered}
P R O_{-} \text {val }=\ln \left(C_{1}\right) \\
C O N_{-} v a l=\ln \left(C_{2}\right)
\end{gathered}
$$

3. 流通业发展城乡结构采用每个地区县以上社会消 费品零售总额 Rta 1 与县以下社会消费品零售总额 Rta 2 的 比值表示。

$$
G_{-} u r=R t a 1 / \text { Rta2 }
$$

4. 技术创新是推动流通业快速发展和区域产业结构 调整的直接动力, 直接促进了社会化生产和专业化生产, 促进产业结构向最优状态调整。本文采用区域专利授予数 量 Pat 来衡量技术创新, 并对数据进行对数处理。

$$
T=\ln (\text { Pat })
$$

5. 外商直接投资规模。外资流入能带动被投资领域在 短时间内迅速发展，使该领域的企业有更多的资金投入， 对地区内的产业优化升级起到推动作用。本文对地区每年 的外资直接投资实际使用量 $F D I$ 进行对数处理。

$$
F O R_{-} \text {inv }=\ln (F D I)
$$

6. 市场化进程。一个地区的市场化发展程度通常伴随 着政策支撑，随着地区市场经济体制的不断完善，外部制 度也不断跟进以推动相关行业的快速发展, 从而促进产业 结构的优化升级。参考国内学者[3]的研究, 市场化进程用 该地区国有固定资产投资额inv1 与该地区全部固定资产

\begin{tabular}{|c|c|c|c|}
\hline 变量类型 & 变量名称 & 指标表示 & 衡量方法 \\
\hline \multirow[t]{2}{*}{ 因变量 } & 产业结构升级指数 & $I U$ & $I U=1 * S_{1}+2 * S_{2}+3 * S_{3}$ \\
\hline & 生产型商贸流通业规模 & $P R O \_v a l$ & $P R O_{-} v a l=\ln \left(C_{1}\right)$ \\
\hline \multirow[t]{3}{*}{ 自变量 } & 消费型商贸流通业规模 & $\mathrm{CON}_{-}$val & $C O N_{-}$val $=\ln \left(C_{2}\right)$ \\
\hline & 商贸流通业城乡差距 & $G_{-} u r$ & $G_{-} u r=R t a_{1} / R_{t a}$ \\
\hline & 技术进步水平 & $T$ & $T=\ln ($ Pat $)$ \\
\hline \multirow{2}{*}{ 控制变量 } & 外商投资规模 & FOR_inv & $F O R_{-} i n v=\ln (F D I)$ \\
\hline & 市场化进程 & Mar & Mar $=i n v_{1} /$ inv $_{2}$ \\
\hline
\end{tabular}
投资额inv2 之比表示。

$$
\text { Mar }=i n v 1 / i n v 2
$$

表1 文章变量选取与衡量方法。

\section{2 . 模型及结果}

根据上文设定的变量, 本文设计三个模型。由于《中 国统计年鉴》中数据统计时间限制, 模型 (1) 和模型 (2) 的考察年限为2004-2015年, 因此模型 (3) 的时间范围为 1995-2008年。

$$
I U=\beta_{0}+\beta_{1} * P R O_{-} v a l+\beta_{2} * T+\beta_{3} * F O R_{-} \text {inv }+\beta_{4} * \text { Mar } 1
$$

$$
\begin{array}{r}
I U=\beta_{0}+\beta_{1} * C O N_{-} v a l+\beta_{2} * T+\beta_{3} * F O R_{-} i n v+\beta_{4} * \text { Mar } 2 \\
I U=\beta_{0}+\beta_{1} * G_{-} u r++\beta_{2} * F O R_{-} i n v+\beta_{3} * \text { Mar } 3
\end{array}
$$

本文选取中国 31 个省及直辖市数据, 采用固定效应模 型, 使用STATA12.0进行数据处理, 并区分东中西三大地 区状况分别探究, 具体模型分析结果如表2-4所示。

表2 生产型商贸流通业与产业结构升级。

\begin{tabular}{llll}
\hline & 东部地区 & 中部地区 & 西部地区 \\
\hline PRO_val & $-0.0648^{* * * *}$ & -0.0014 & $0.0604^{* * *}$ \\
& $(0.0231)$ & $(0.0182)$ & $(0.0123)$ \\
$T$ & $0.0198^{* * *}$ & -0.0119 & -0.0102 \\
& $(0.0098)$ & $(0.0076)$ & $(0.0082)$ \\
FOR_inv & -0.0087 & $0.0109^{*}$ & $0.0075^{* *}$ \\
& $(0.0087)$ & $(0.0065)$ & $(0.0034)$ \\
Mar & -0.0107 & $0.259^{* * *}$ & $\left(0.1207^{* *}\right.$ \\
& $(0.0202)$ & $(0.0616)$ & $2.0142^{* * *}$ \\
${ }_{\text {cons }}$ & $2.6528^{* * *}$ & $2.2852^{* * *}$ & $(0.0963)$ \\
$N$ & $(0.1782)$ & $(0.1374)$ & 132 \\
$R^{2}$ & 132 & 108 & 0.7080 \\
\hline
\end{tabular}

注: * ***、***分别表示在 $10 \% 、 5 \%$ 和 $1 \%$ 的水平上显著, 没有标注 $*$ 表示变量在模型中回归结果不显著; 括号中数字表示标准差, 回归结果由STATA 12.0 给出。

生产型流通业规模的扩大对东中西三个地区的影响 不同。对于东部地区，生产型流通业规模每扩大 $1 \%$, 将 引起产业结构升级指数降低 $0.064 \%$; 中部地区两者无显著
相关性；西部地区生产型流通业规模每扩大 $1 \%$ 将促进其 产业结构升级 $0.0604 \%$ 。

出现上述结果可能原因为: 中国东部地区经济发达, 北 上广深这类一线城市，金融、信息等服务业逐渐取代传统制 
造工业的主导地位, 消费型商贸流通业在其产业结构升级中 扮演更重要的位置, 生产型消费流通业的过度发展会在一定 程度上占据了消费型流通业的人力等资源, 因此会对产业升 级产生负向作用。而西部地区处于加速发展阶段, 很多工业
企业相继落地重庆、成都、西安等城市, 生产型商贸流通业 的发展可以为这些地区工业发展添翼, 完善为工业企业服务 的配套体系, 从而对产业升级有正向影响。

表3 消费型商贸流通业与产业结构升级。

\begin{tabular}{llll}
\hline & 东部地区 & 中部地区 & 西部地区 \\
\hline CON_val & $0.1389^{* * * *}$ & $0.0726^{* *}$ & $0.0329^{* * *}$ \\
& $(0.0191)$ & $(0.0305)$ & $(0.0105)$ \\
$T$ & -0.0009 & $0.0139^{*}$ & -0.0074 \\
& $(0.0081)$ & $(0.0074)$ & $(0.0086)$ \\
FOR_inv & $0.0127^{*}$ & $0.0126^{*}$ & 0.0057 \\
& $(0.0074)$ & $(0.0064)$ & $(0.0037)$ \\
Mar & -0.0006 & $0.2168^{* * *}$ & $0.1231^{*}$ \\
& $(0.0173)$ & $(0.0601)$ & $(0.0037)$ \\
${ }_{\text {cons }}$ & $1.5619^{* * * *}$ & $1.8234^{* * *}$ & $2.1247^{* * *}$ \\
$N$ & $(0.1728)$ & $(0.2021)$ & $(0.0996)$ \\
$R^{2}$ & 132 & 108 & 132 \\
\hline
\end{tabular}

注: 同表2。

消费型商贸流通业规模每扩大 $1 \%$ ，东中西部产业升 级指数分别提高 $0.1389 \% 、 0.0762 \%$ 和 $0.0329 \%$ 。虽然中国 东中西部三大地区目前经济发展动力不同, 发展程度不一 致，但是消费型商贸流通业更多地促进服务性行业如旅游
业的发展，产业结构升级指数就是按照第一、第二、第三 产业发展重要性依次递增来构造, 因此消费型流通业对中 国三大地区产业结构升级均存在显著的正向影响。

表4 商贸流通业城乡结构差异与产业结构升级。

\begin{tabular}{llll}
\hline & 东部地区 & 中部地区 & 西部地区 \\
\hline \multirow{2}{*}{$G_{-} u r$} & $-0.0431^{* * *}$ & -0.0264 & $0.1000^{* * *}$ \\
FOR_inv & $(0.0090)$ & $(0.0331)$ & $(0.0127)$ \\
& $0.0197^{* * *}$ & $0.017^{* *}$ & 0.0002 \\
Mar & $(0.0060)$ & $(0.0058)$ & $(0.0046)$ \\
& $0.0223^{* * *}$ & $0.1573 * 0599$ \\
cons & $(0.0075)$ & $(0.0534)$ & -0.0599 \\
$N$ & $1.9779^{* * *}$ & $1.8535^{* * *}$ & $(0.0399)$ \\
$R^{2}$ & $(0.0731)$ & $(0.0619)$ & $\left(.9249^{* * *}\right.$ \\
\hline
\end{tabular}

注: 同表2。

从商贸流通业城乡发展差距对东部产业结构升级的 显著负向影响可以看出, 流通城乡发展不平衡是阻碍东部 地区产业结构升级的重要原因之一。中部地区流通城乡差 距与产业结构升级不存在相关性, 西部地区反而受到该差 距的促进作用。东部地区相对落后的农村地区商贸流通市 场与其发达城市内部的高效率、现代化的流通市场相关性 较高, 因此两者发展不平衡降低流通效率, 对地区产业升 级造成障碍。而西部地区目前主要发展动力集中在城市, 发展落后的农村地区以第一产业作为主要收入来源, 因此 商贸流通业城乡发展差距使得政府集中资源来推动城市 发展, 减少落后地区对资源的分配, 反而对这些地区短时 间内的产业结构升级有利。

\section{4. 研究结论与政策建议}

\section{1. 研究结论}

经过上述研究结果可得出如下结论：（1）中国生产 型商贸流通业发展规模对东部和西部地区产业升级分别
存在促进作用和负向影响，对中部地区无影响。（2）消 费型商贸流通业发展规模流通业对三个地区均存在显著 正向影响, 但对东西部地区的影响强于中部地区。（3） 商贸流通业发展城乡差距对东部和西部地区产业结构升 级分别存在阻碍和促进作用, 对中部地区则无显著影响。 （4）技术进步对西部地区产业升级无相关性, 东部地区 技术进步对产业升级的促进作用强于中部地区。（5）中 国外商投资规模和市场化程度指标对三大地区产业升级 均存在促进作用。

\section{2. 政策建议}

中国东部地区第三产业在经济中的作用大于第二和 第三产业, 应加大对消费型商贸流通业的投入使其更好地 服务于第三产业，但要注重协调商贸流通业城乡之间的发 展平衡, 甚至将资源更多地向乡镇倾斜, 减少城乡流通业 发展差异对产业结构升级的阻碍作用。

西部城市的第二产业近些年得到飞速发展，但由第二 产业向第三产业的过渡仍然不足, 支持工业企业发展的生 产型流通业对西部地区的产业结构升级承担重要责任。消 
费型商贸流通业虽然可以为地区创造发展第三产业的良 好环境，但是其影响效果不如生产型流通业显著。同时西 部流通业对农村的推动作用远不如城市地区，因此地方政 府可以优先考虑扶持城市商贸流通业的发展, 在城市产业 升级完美转型之后, 以吸收劳动力和各类土地资源的方式 去辐射带动农村地区的发展。

中国中部地区产业升级状况总体上来说受流通业发 展状况影响不是很明显, 可能是因为中部地区的经济发展 特征不如东西部地区明显, 因此加大科技投入、实行经济 全球化方针、吸引外资等方式对中部地区的产业升级具有 更大的意义。

\section{参考文献}

[1] 赵公民, 王稼琼. 流通产业对经济增长的贡献分析一以山 西省为例 $[J]$. 生产力研究, 2009(18):137-138。

[2] 王晓东, 谢莉娟. 论流通产业结构调整与就业增长一一基于 中部地区流通业对就业吸纳的贡献分析 [J]. 财贸经 济. 2010(2):7-14。

[3] 樊纲, 王小鲁, 马光荣. 中国市场化进程对经济增长的贡献 [J].经济研究, 2011(9):4-16。

[4] 吴沉, 王传维.流通产业在我国产业结构优化中的作用 [J]. 商业经济与管理，2000(12):14-16。

[5] 中国社会科学院财政与贸易经济研究所课题组, 宋则, 赵 凯. 中国商贸流通服务业影响力研究 [J]. 经济研究参考, 2009(31):2-9。
[6] 杨以文. 商贸流通业的发展效应研究——以江苏为例 [J]. 江 苏第二师范学院学报, 2011(2):101-105。

[7]朱黎明, 刘彦志.不同类型流通产业对我国产业结构变迁影 响实证分析 [J]. 商业时代, 2014(11):4-6。

[8] 宋艳萍. 商贸流通业在我国产业体系中的动态角色扮演 [J]. 商业时代, 2015(6):33-35。

[9] 张得银. 流通驱动区域产业结构升级的微观机理一一基于 省际面板数据的实证检验 $[\mathrm{J}]$. 山西财经大学学报, 2015, 37(12):51-60。

[10] 李罗. 商贸流通发展与我国产业结构升级耦合效应研究 [J]. 商业时代, 2015(13):4-6。

[11] 车久菊. 流通业发展规模、要素投入对产业结构调整的作用 机理-以长三角经济圈为例 [J]. 商业时代, 2016(11):190-191。

[12] 王志楠, 韩朝怡. 我国流通产业对三次产业发展影响的实证 分析[J]. 中国市场, 2017(11):71-71。

\section{作者简介}

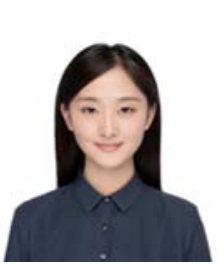

张艺馠 (1992-), 女, 安徽桐城人, 上海大 学产业经济学专业硕士研究生, 主要研究方 向：企业创新、产业升级。 